\title{
Avaliação da produção de leite e contagem de células somáticas em bovinos leiteiros suplementads com Saccharomyces cerevisiae como fonte de zinco orgânico ${ }^{1}$
}

\section{Evaluation of milk production and somatic cell count of dairy cow supplemented with Saccharomyces cerevisiae as a source of organic zinc}

\author{
Luiz Fernando Coelho da Cunha Filho ${ }^{2 *}$; Simone Biagio Chiacchio ${ }^{3}$; \\ Roberto Calderon Gonçalves ${ }^{3}$; Paulo Eduardo Pardo ${ }^{4}$; \\ Laurenil Gaste ${ }^{5}$; Werner Okano ${ }^{2}$; Adalberto José Crocci ${ }^{6}$
}

\section{Resumo}

\begin{abstract}
Com o objetivo de avaliar a produção de leite e a contagem de células somáticas de bovinos leiteiros, suplementados com Saccharomyces cerevisiae, como fonte de zinco orgânico, por 180 dias, foram separadas aleatoriamente 25 vacas holandesas, em um rebanho de 189 vacas em lactação. Os animais foram distribuídos em dois grupos, sendo grupo 1 (G1) composto por 10 vacas suplementadas e grupo 2 (G2) 15 animais sem suplementação. A produção de leite foi mensurada pelo controle leiteiro oficial da Associação Paranaense de Criadores de Bovinos da Raça Holandesa em sete momentos durante os 180 dias. As amostras de leite foram coletadas de cada animal, sendo submetidas à contagem eletrônica de células somáticas. Os resultados demonstram que a suplementação de zinco orgânico não alterou a produção de leite, contudo foi capaz de manter baixa a contagem de células somáticas. Os dados do presente trabalho sugerem que utilizar suplementação de zinco orgânico na dieta de vacas leiteiras, aumente a qualidade do leite produzido e conseqüentemente a remuneração para o produtor.
\end{abstract}

Palavras-chave: Bovinos de leite, células somáticas, Saccharomyces cerevisiae, zinco

\begin{abstract}
The aim of the evaluation of milk production and somatic cell count of dairy cow supplemented with Saccharomyces cerevisiae as a source of organic zinc for 180 days, 25 Holstein cows were selected, randomly chosen from a flock of 189 lactating cows. The animals were distributed in two groups, namely group 1 (G1) which holded 10 cows supplemented and group 2 (G2) with 15 animals without supplementation. The production of milk was measured by the control official milkman of the Assocition Paranaense of Creators of Bovine of the Holstein in seven moments during the 180 days. The samples of
\end{abstract}

\footnotetext{
1 O presente artigo foi redigido como parte dos requisitos para obtenção do título de Doutor, junto ao Programa de Pós-Graduação em Medicina Veterinária da Faculdade de Medicina Veterinária e Zootecnia - UNESP.

2 Departamento de Clínica Médica de Ruminantes, Universidade Norte do Paraná (UNOPAR), Arapongas, PR. E-mail: luiz.cunha@unopar.br.

3 Departamento de Clínica Veterinária, Universidade Estadual Paulista (UNESP), Botucatu, SP.

4 Departamento de Clínica Veterinária, Universidade do Oeste Paulista (UNOESTE), Presidente Prudente, SP.

5 Departamento de Clínicas Veterinárias, Universidade Estadual de Londrina (UEL), Londrina, PR.

${ }^{6}$ Departamento de Bioestatística, Instituto de Biociências, UNESP, Botucatu.

* Autor para correspondência
} 
milk were collected of each animal, being submitted to the electronic counting of somatic cells. The results demonstrate that the supplemented of organic zinc didn't alter the production of milk, however it was capable to maintain low the counting of somatic cells. The data of the present work suggest that to use supplemented of organic zinc in the diet of cows milk, increase the quality of the produced milk and consequently the remuneration for the producer.

Key words: Dairy cow, somatic cell, Saccharomyces cerevisiae, zinc

\section{Introdução}

O Brasil é o sexto maior produtor em volume de leite do mundo, cerca de 21 bilhões de litros em 2001 (UNITED STATES OF AMERICA, 2002). O agronegócio do leite e de seus derivados desempenha um papel relevante no suprimento de alimentos e na geração de emprego e renda. Para cada real de aumento na produção no sistema agroindustrial do leite há um crescimento de, aproximadamente, cinco reais no PIB, o que coloca o agronegócio do leite à frente de setores importantes como o da siderurgia e o da indústria têxtil (VILELA, 2002).

Entretanto, com o aumento da demanda mundial por produtos de origem animal, foi intensificada a produção animal, e conseqüentemente ocorreu diminuição no bem-estar animal, conduzindo a uma freqüência maior de doenças (SILVA et al., 2005). Dessa forma, a busca de soluções para este problema é uma constante entre os buiatras, tornandose uma importante linha de pesquisa na pecuária leiteira moderna.

A levedura Saccharomyces cerevisiae, crescendo em meio contendo uma elevada quantidade de cátions metálicos (zinco), pode acumular esses metais em suas células (VOLESKY, 1990), e, portanto transformar uma fonte inorgânica de metal, em uma fonte orgânica.

O zinco acelera a cicatrização das feridas, aumenta a velocidade de reparação do tecido epitelial e mantêm a integridade celular. $\mathrm{O}$ zinco também é necessário para a síntese e maturação da queratina (WHITAKER et al., 1997; SMART; CILBALUK, 1997).

A alimentação de vacas com zinco orgânico, teve impacto positivo na produção de leite, e reduziu significativamente a contagem de células somáticas (POPOVIC, 2004).
A absorção do zinco pelo animal está diretamente relacionada com as suas necessidades (BOOTH; McDONALD, 1992; PEIXOTO; MOURA; FARB, 1995). Um animal com alta produção de leite absorve mais zinco do que aquele com requerimentos mais baixos. Na lactação a vaca excreta pelo leite cerca de $4 \mathrm{mg}$ de zinco por quilograma de leite produzido. A absorção é menor no animal pré-ruminante alimentado com farelo de soja devido à presença do ácido fítico (PEIXOTO; MOURA; FARB, 1995).

A excreção de zinco ocorre na maior parte através das fezes, também ocorre excreção pela urina, leite, sêmen, suor, pêlo e descamação da pele (MAHAN; STUMP, 1998; WAITZBERG, 2004).

A deficiência de zinco resulta em uma variedade de "defeitos imunológicos", como a atrofia tímica, linfopenia, resposta proliferativa de linfócitos reduzida a mitógenos, diminuição seletiva de linfócitos $\mathrm{T}$ auxiliares e atividade celular diminuída das células NK e atividade hormonal tímica deficiente (SMART; GUDMUNDSON; CHRISTENSEN, 1981; MAHAN; STUMP, 1998; AMORIM, 2002).

A cicatrização das feridas está prejudicada na deficiência de zinco, devido ao papel básico do zinco na síntese do RNA (BOOTH; McDONALD, 1992). $\mathrm{Na}$ falta de níveis adequados de zinco as células epiteliais e fibroblasto, podem migrar normalmente, porém sem se multiplicar, prejudicando a epitelização e a síntese de colágeno, acarretando em inadequada cicatrização (PROBST, 1999).

Moraes (1998) avaliou as concentrações de zinco no fígado de bovinos e ovinos de várias regiões do Brasil, observou que as concentrações estavam dentro dos parâmetros de normalidade (101 a 200 ppm), sendo que somente em algumas regiões apresentaram valores um pouco abaixo. Armelin, 
Piasentin e Primaesi (2002) realizaram um estudo no Brasil com diversos tipos de forragens, e concluíram que quando forragens tropicais forem utilizadas na alimentação de vacas de leite, a dieta geralmente deve ser completada com a adição do elemento zinco.

Há grande margem de segurança entre o consumo normal e a quantidade tóxica de zinco, sendo o nível máximo estimado na dieta de $1000 \mathrm{mg}$ para bovinos adultos (ANDRIGUETTO et al., 1990). Mahan e Stump (1998) enfatizam que o excesso da ingestão oral de zinco ao ponto de toxicidade é raro.

Rebhun (2000) descreve que a intoxicação por zinco pode ocorrer em bezerros de corte alimentados com substitutos de leite e bovinos adultos que receberam água contaminada com o mineral.

As principais fontes adicionadas à dieta são os óxidos, sulfatos, cloretos, acetatos, denominados como fonte de zinco inorgânico. Quelatos, transquelatos e a levedura viva de cerveja são fontes orgânicas de zinco (McDOWELL, 1996; MACHADO, 1997; HATFIELD et al., 2001).

As fontes minerais orgânicas são biodisponíveis e mais facilmente absorvidas que as fontes minerais inorgânicas (ECKERT; GREENE; CARSTENS, 1999). O zinco derivado de fontes orgânicas mostrouse duas vezes mais biodisponível que o elemento associado a uma fonte inorgânica, e ainda demonstrou uma redução na contagem das células somáticas e da mastite clínica (CLOSE, 1998).

A Agência de Inspeção de Alimentos Canadense (Canadian Food Inspection Agency - CFIA) apresenta na sua classificação uma forma de mineral denominada de metal levedura desidratada (levedura enriquecida com mineral), que consiste de um produto seco composto de levedura produzida de um gênero não modificado de Saccharomyces e o meio no qual ela cresceu. Este meio não deve ser enriquecido com níveis de minerais acima da exigência para o crescimento da levedura com a exceção do metal em questão (LANGWINSKI; PATIÑO, 2001).
A mastite é de caráter infeccioso, podendo ser classificada como clínica ou subclínica (BLOOD; RADOSTITS, 1994; RIBEIRO et al., 2003). Na forma subclínica não se observam alterações macroscópicas e sim alterações na composição do leite; portanto não apresenta sinais visíveis de inflamação do úbere (CULLOR; TYLER; SMITH, 1994), porém o leite apresenta alta contagem de células somáticas (CCS).

A forma subclínica é responsável por aproximadamente $70 \%$ das perdas por mastite (PHILPOT, 1984), podendo reduzir a produção de leite em níveis que variam de 10 a $26 \%$ do total da produção de acordo com grau de intensidade do processo inflamatório, da prevalência da doença, do agente infeccioso, da patogenicidade e do estágio da lactação (RATNAKUMAR; HAMZA; CHOUDHURI, 1996).

A adição de um ou mais minerais traço orgânicos na dieta de bovinos, tem aumentado a produção de leite e a resposta imune em alguns estudos (SPEARS, 1996).

Comparativamente aos outros oligoelementos minerais, o zinco é encontrado em taxas relativamente altas no leite de bovinos, de 3,0 a 5,0 mg/ L (LUCCI, 1997; ANDRIGUETTO et al., 1990; MILLER; JARVIS; McBEAN, 2000). Etcheverry et al. (2004) avaliaram que o colostro e o leite possuem a mesma biodisponibilidade de minerais, não havendo portanto, diferenças entre eles. Entretanto, Maynard et al. (1984) afirmaram que o colostro possui maior concentração de zinco.

Aumento na produção de leite e a diminuição na contagem de células somáticas, foram observadas na lactação de vacas leiteiras alimentadas com zinco orgânico (AGUILAR; KUJAWA; OLSON, 1988; KELLOG; RAKES; GLIEDT, 1989; HERRICK, 1989; GALTON, 1990; AGUILAR; JORDAN, 1990; SPEARS, 1996; NOCEK; PATTON, 2002).

O papel do zinco na manutenção da integridade epitelial dos tecidos é evidente (MILLER; RAMSEY; MADSEN, 1988). O zinco também diminui a invasão 
de patógenos na mama por seu papel na produção da queratina do teto. A queratina de revestimento do canal do teto atrai as bactérias e previne a penetração delas para dentro da mama (CRAVEN; WILLIAMS, 1985; NICKERSON, 1990). Aproximadamente 40\% da queratina de revestimento do canal do teto das vacas holandesas é removida no processo de ordenha, assim ela requer contínua regeneração (CAPUCO et al., 1992).

Hardin e Thorne (1993) ao contrário de outros relatos, não observaram mudanças na produção de leite e na contagem de células somáticas nos animais suplementados com zinco. Determinaram que havia uma variação semanal muito grande na contagem de células somáticas dentro dos grupos tratados, e que esse é um comportamento típico em dados de CCS.

O objetivo da pesquisa foi avaliar o efeito da suplementação com Saccharomyces cerevisiae, como fonte de zinco orgânico, na dieta de vacas leiteiras, sobre a produção de leite e contagem de células somáticas.

\section{Material e Métodos}

O estudo foi realizado entre novembro de 2003 a maio de 2004, em colaboração com o Departamento de Clínica Veterinária da Faculdade de Medicina Veterinária e Zootecnia da UNESP - Campus de Botucatu - SP, Centro Diagnóstico da Universidade Norte do Paraná - Campus Arapongas - PR, Alltech do Brasil e a propriedade "Sítio Yamamoto", município de Rio Bom - PR.

A propriedade de 134 ha possui solo latossolo vermelho, com altitude média de $480 \mathrm{~m}$, latitude $23^{\circ}$ $45^{\prime} 10^{\prime \prime} \mathrm{S}$ e longitude $51^{\circ} 24^{\prime} 50^{\prime \prime} \mathrm{W}$, clima subtropical úmido mesotérmico, com regime pluvial de setembro a abril e período seco e frio de maio a agosto.

\section{Formação dos Grupos de Animais}

Os animais utilizados pertenciam a um plantel de criação intensiva e produtora de leite do tipo B, formado por vacas da raça Holandesa variedade preto e branco, pura de origem, entre o $1^{\circ}$ e o $3^{\circ}$ mês de lactação, produzindo em média, $23 \mathrm{~kg} / \mathrm{leite} / \mathrm{dia}$, com idade entre 2,5 e 6 anos, peso médio corporal de $500 \mathrm{~kg}$. Os animais foram identificados por meio de brincos (PVC). O rebanho foi mantido em regime de confinamento (free-stall), em piso de concreto. Durante o transcorrer do experimento, todos os animais receberam o mesmo manejo e a mesma alimentação, distribuída em duas porções iguais diárias, constituídas no total por $35 \mathrm{~kg}$ de silagem de milho, acrescidos de $8 \mathrm{~kg}$ de concentrado ${ }^{7}$, e mistura mineral ${ }^{8} \mathrm{e}$ água ad libitum. A dieta básica atende as exigências nutricionais, conforme o (NATIONAL RESEARCH COUNCIL, 2001).

Do plantel de 189 vacas em lactação, foram selecionados, dentre os animais que estavam no início da lactação, 25 animais aleatoriamente escolhidos, de modo a formarem dois grupos, o grupo G1 com 10 animais e o grupo G2 com 15 animais.

\section{Suplementação de Zinco}

O período experimental foi dividido em dois, um de 25 dias, no qual os animais se adaptaram ao manejo (free-stall) e a alimentação (dieta basal), seguido de outro de 180 dias, no qual foi fornecido além da dieta basal uma suplementação de $5 \mathrm{~g}$ de levedura de $S$. cerevisae ${ }^{9}$, como fonte de zinco, representando uma suplementação de $750 \mathrm{mg} / \mathrm{vaca} / \mathrm{dia}$.

Os dois grupos ficaram assim dispostos quanto à dieta: Grupo 1, animais que receberam suplementação de $5 \mathrm{~g} /$ dia de levedura de $S$. cerevisiae e Grupo 2 que não receberam suplementação de zinco.

${ }^{7}$ Colari $20 \%{ }^{\circledR}$

${ }^{8}$ Fosbov 20 Tortuga ${ }^{\circledR}$

${ }^{9}$ Bioplex Zinco Alltech ${ }^{\circledR}$ 
Determinação da Produção de Leite e da Contagem de Células Somáticas

O rebanho da propriedade é submetido mensalmente ao controle leiteiro oficial pela Associação Paranaense de Criadores de Bovinos da Raça Holandesa (APCBRH). Os animais do experimento também foram submetidos ao controle leiteiro, e através da análise do relatório de número 2 da APCBRH, sumário de células somáticas e produção, foram determinadas a produção leiteira e a CCS, em sete momentos, de novembro de 2003 a maio de 2004.

Foram coletados para a CCS em frascos padronizados de $40 \mathrm{~mL}$, contendo conservante Bronopol $^{\circledR}$, leite de todos os quartos de cada vaca da ordenha da manhã e tarde, identificados, homogeneizados e acondicionados em caixas apropriadas. As amostras foram encaminhadas ao laboratório central de análises do programa de análise de rebanhos leiteiros do Paraná (APCBRH), onde foram submetidas ao método de contagem eletrônica de células somáticas ${ }^{10}$.

\section{Análise Estatística}

Para a variável produção de leite, os grupos foram comparados pela análise multivariada de perfil (MORRISON, 1990) com avaliações, em média, nos vários momentos estudados. $\mathrm{O}$ delineamento foi inteiramente ao acaso. A comparação estatística dos resultados obtidos das mensurações da produção de leite foi submetida à análise de variância (ANOVA), seguida pelo teste de Tukey, para comparação de médias $(\mathrm{P} £ 0,05)$.

Para a contagem de células somáticas foi utilizada a análise não paramétrica com aplicação do teste de Friedman para comparação dos momentos, em cada grupo, e teste de Kruskal-Wallis para comparação de grupos em cada momento (ZAR, 1996).

\section{Resultados e Discussão}

\section{Produção de leite em vacas suplementadas}

A produção média de leite dos 2 grupos, durante os 180 dias do experimento, não apresentou diferenças significativas estatisticamente, conforme a tabela 1. Assim sendo, a suplementação oral de levedura viva como fonte de zinco não alterou a produção de leite, conforme ilustra a figura 1.

Tabela 1. Médias da produção de leite em litros por vaca dia, nos grupos tratados (G1) e controle (G2), em 7 momentos (M) mensais nos 180 dias do experimento.

\begin{tabular}{cccccccc}
\hline Grupos & $\begin{array}{c}\text { Momentos } \\
\text { M0 }\end{array}$ & M1 & M2 & M3 & M4 & M5 & M6 \\
\hline G1 & $30,6^{\mathrm{a}}$ & 27,7 & 29 & 27,2 & $27,6^{\mathrm{a}}$ & 25,6 & 24,7 \\
G2 & $25,3^{\mathrm{b}}$ & 23,7 & 23,5 & 22,7 & $21,2^{\mathrm{b}}$ & 19,8 & 19,7 \\
\hline
\end{tabular}

Letras minúsculas comparam médias entre grupos. Médias seguidas de pelo menos uma letra igual não diferem significativamente $(\mathrm{P}>0,05)$.

\footnotetext{
${ }^{10}$ Bentley Somacount 500
} 


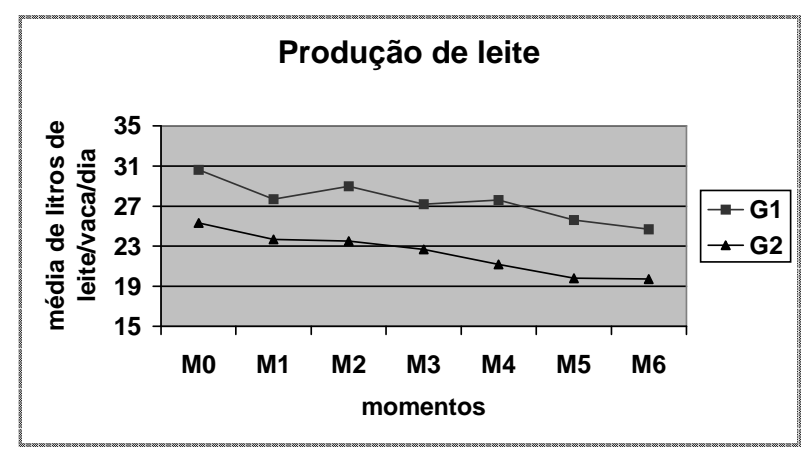

Figura 1. Médias da produção de leite em litros por vaca dia, nos grupos tratados (G1) e controle (G2), em 7 momentos (M) mensais nos 180 dias do experimento.

A busca de maior produtividade utilizando microminerais na dieta vem de longa data, Galvão, Mello e Silva (1973) forneceram zinco via oral para vacas em lactação e não obtiveram resultados positivos para produção de leite, resultado que também foi confirmado neste estudo. A justificativa para a suplementação com zinco é baseada em três hipóteses: na melhora da resposta imunológica da glândula mamária frente à quadros de mastite; na mais rápida e melhor queratinização do canal do teto; na maior excreção de zinco pelo leite em vacas de alta produção.

Os resultados desta pesquisa confirmam os achados de Smith, Amos e Froetschel (1997), que também não observaram aumento na produção de leite em vacas suplementadas com zinco orgânico por 180 dias. Neste aspecto, é interessante salientar que a variabilidade na produção de leite entre rebanhos, é muito grande, devido a fatores como a resistência individual dos animais à mastite, a conversão alimentar de cada animal, a idade do animal, o número de lactações, a resposta ao estresse térmico, entre outros.

Por outro lado, os dados do presente estudo discordam dos resultados obtidos por Aguilar, Kujawa e Olson (1988), Kellogg, Rakes e Gliedt (1989) e Popovic (2004), que constataram aumento na produção de leite de vacas alimentadas com zinco orgânico. Contudo Kellogg, Rakes e Gliedt (1989) consideraram como significância estatística entre os grupos um intervalo muito amplo, onde o valor de "P" foi menor ou igual a 0,10 .

Contagem de células somáticas no leite de vacas suplementadas

A CCS no leite dos animais do grupo 2 (G2 controle) apresentou aumento significativo estatisticamente, conforme a tabela 2. Portanto, podese atribuir a suplementação oral de levedura viva como fonte de zinco, o fato da contagem de células somáticas nos animais manter-se baixa, conforme ilustra a figura 2 .

Tabela 2. Mediana da contagem de células somáticas (1000/mL) por vaca, nos grupos tratado (G1) e controle (G2) em 7 momentos $(\mathrm{M})$ mensais nos 180 dias do experimento.

\begin{tabular}{cccccccc}
\hline \multirow{2}{*}{ Grupos } & Momentos & \multicolumn{1}{c}{} & & & & \\
\cline { 2 - 7 } & M0 & M1 & M2 & M3 & M4 & M5 & M6 \\
\hline G1 & 47 & 50 & 30 & 62,5 & 63,5 & 66,5 & 73 \\
G2 & $44^{\mathrm{A}}$ & $94^{\mathrm{B}}$ & $116^{\mathrm{B}}$ & $115^{\mathrm{B}}$ & $97^{\mathrm{B}}$ & $109^{\mathrm{B}}$ & $155^{\mathrm{B}}$ \\
\hline
\end{tabular}

Letras maiúsculas comparam médias dentro de cada grupo.

Médias seguidas de pelo menos uma letra igual não diferem significativamente $(\mathrm{P}>0,05)$. 


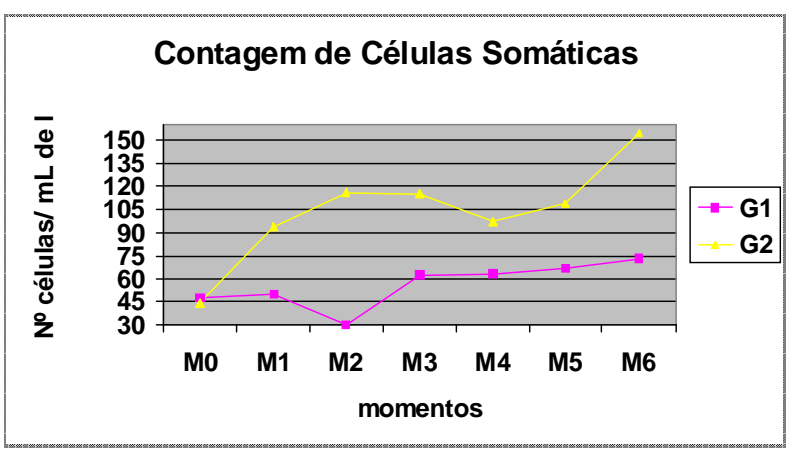

Figura 2. Mediana da contagem de células somáticas (1000/ $\mathrm{mL})$ por vaca, nos grupos tratado $(\mathrm{G} 1)$ e controle $(\mathrm{G} 2)$ em 7 momentos (M) mensais nos 180 dias do experimento.

A diminuição na CCS de vacas leiteiras em lactação, alimentadas com zinco orgânico, foi observada por Aguilar, Kujuwa e Olson (1988), Kellogg, Rakes e Gliedt (1989), Galton (1990), Aguilar e Jordan (1990), Hansen (1992), Spears (1996), Popovic (2004), Kellogg et al. (2004) e Pereira et al. (2005), confirmando os resultados do presente trabalho.

A manutenção da CCS das vacas suplementadas neste experimento pode ser explicada pelos trabalhos de Craven e Williams (1985) e Nikerson (1990), que demonstraram o aumento na produção de queratina no canal do teto de vacas suplementadas com zinco mais biodisponível, prevenindo a penetração de bactérias para entro da mama.

Corrobora com esse entendimento as afirmações de Fonseca e Santos (2000) quando asseveram que o zinco possui função essencial na integridade da pele, em especial da glândula mamária e na proteção das membranas celulares contra a ação oxidativa dos radicais livres.

Sabe-se que a mastite subclínica é responsável pela redução da produção de leite (REBHUN, 2000) em níveis que variam de 10 a $26 \%$ (RATNAKUMAR; HAMZA; CHOUDHURI, 1996), entretanto neste estudo apesar da suplementação de zinco orgânico manter baixa a contagem de células somáticas (tabela 2), este fator não foi suficiente para influenciar a produção de leite (tabela 1).
Hardin e Thorne (1993) ao contrário deste relato, não observaram mudanças na CCS nos animais suplementados com zinco orgânico. Todavia, determinaram que havia uma variação semanal muito grande na CCS dentro dos grupos tratados, e que esse comportamento típico das células somáticas poderiam influenciar os resultados.

\section{Conclusão}

A suplementação oral de $750 \mathrm{mg}$ de zinco orgânico para vacas em lactação por 180 dias não alterou a produção de leite, entretanto a suplementação manteve baixa a contagem de células somáticas.

\section{Referências}

AGUILAR, A. A.; JORDAN, C. D. Effects of zinc methionine supplementationin high producing Holstein cows early in lactation. In: ANNUAL MEETING NATIONAL MASTITIS COUNCIL, 29., 1990, New York. Proceedings... New York: INCP, 1990. p.187.

AGUILAR, A. A.; KUJAWA, M.; OLSON, J.D.Zinc methionine supplementation in lactating dairy cows. In: ANNUAL MEETINGNATIONALMASTITISCOUNCIL, 27., 1988, New York. Proceedings... New York: INCP, 1988. p.119.

AMORIM, R. M. Valores séricos e hepáticos de elementos minerais, atividade sérica da ceruloplasmina, hemograma, proteinograma e metabolismo oxidativo dos neutrófilos em bezerros da raça nelore, nascidos de mães com nutrição adequada ou inadequada em cobre e zinco. 2002. Tese (Doutorado em Medicina Veterinária) Faculdade de Medicina Veterinária e Zootecnia, Universidade Estadual Paulista, Botucatu.

ANDRIGUETTO, J. M.; PERLY,L.; MINARD, I.; GEMAEL, A.; FLEMMING, J. S.; SOUZA, G. A.; BONA FILHO, A. Nutrição animal. São Paulo: Nobel, 1990. v.1.

ARMELIN, M. J.; PIASENTIN, R. M.; PRIMAESI, O. Neutron activation analysis of zinc in forages used in intensive dairy cattle production systems. Journal of Radioanalytical and Nuclear Chemistry, Lousanne, v.252, p.585-587, 2002.

BLOOD, D. C.; RADOSTITS, O. M. Clínica veterinária. 7.ed. Rio de Janeiro: MMFreire, 1994.

BOOTH, N. A.; McDONALD, L. E. Farmacologia e terapêutica em veterinária. 6.ed. Rio de Janeiro: Guanabara Kogan, 1992. 
CAPUCO, A. V.; BRIGHT, S. A.; PANKEY, J. W.; WOOD, D. L.; MILLER, R. H.; BITMAN, J. Increased susceptibility to intramammary infection following removal of teat canal Keratin. Journal of Dairy Science, Champaign, v.75, n.8, p.2126-2130, aug. 1992.

CLOSE, H. W. Biodisponibilidade é a chave para uma suplementação mineral de sucesso. Feed Times, Dublin, v.3, n.2, p.37-39, 1998.

CRAVEN, N.; WILLIAMS, M. R. Defenses of the bovine mammary gland against infection and prospects for their enhancement. Veterinary Immunology and Immunopathology, Amsterdam, v.10, n.1, p.71-127, 1985.

CULLOR, J. S.; TYLER, J. W.; SMITH, B. P. Distúrbios da glândula mamária. In: SMITH, B. P. Tratado de medicina interna dos grandes animais. São Paulo: Manole, 1994. v.2.

ECKERT, E. G.; GREENE, W. L.; CARSTENS, E. G. Coppers status of ewes fed incrasing amounts of cooper, from copper sulfate or copper proteinate. Journal of Animal Science, Champaign, v.77, p.244-249, 1999.

ETCHEVERRY, P.; WALLINGFORD, J. C.; MILLER, D. D.; GLAHN, R. P. Calcium, zinc, and iron biovailabilities from a commercial human milk fortifier: a comparison study. Journal of Dairy Science, Champaign, v.87, n.11, p.36293637, nov. 2004.

FONSECA, L. F. L.; SANTOS, M. V. Qualidade do leite e controle de mastite. São Paulo: Lemos, 2000.

GALTON, D. M. Mastitis control. In: Proc. Of seminar on Zinc Supplementation for dairy Cattle. Zimpro Corp. Edina, 1990.

GALVÃO, F. E.; MELLO, R. P.; SILVA, R. M. Efeito da suplementação de zinco à dieta de vacas em lactação. Arquivos da Escola de Veterinaria da Universidade de Minas Gerais, Belo Horizonte, v.25, n.3, p.235-241, 1973.

HANSEN, R. Effects of bioplex zinc supplementation on somatic cell counts in three high producing dairy herds. In: ANNUAL SYMPOSIUM ON BIOTECHNOLOGY IN THE FEED INDUSTRY, 8., 1992, Lexington. Proceedings... Lexington: editora, 1992. p.

HARDIN, D. K.; THORNE, J. G. Effects of bioplex zinc or zinc oxide on mastitis incidence in lactating dairy cows. In: ANNUAL SYMPOSIUM ON BIOTECHNOLOGY IN THE FEED INDUSTRY, 9., 1993, Lexington. Proceedings... Lexington: editora, 1993. p.

HATFIELD, P. G.; SWENSON, C. K.; KOTT, R. W.; ANSOTEGUI, R. P.; ROTHS, N. J.; ROBINSON, B. L. Zinc and copper status in ewes supplemented with sulfate and amino acid-complexed forms of zinc and copper. Journal of Animal Science, Champaign, v.79, n.1, p.261-266, 2001.
HERRICK, J. Zinc methionine: feedlot and dairy indications. Large Animal Practic, Mission Viejo, v.44, p.35-37, 1989.

KELLOGG, D. W.; RAKES, J. M.; GLIEDT, D. W. Effect of zinc methionine supplementation on performance and selected blood parameters of lactating dairy cows. Nutrition Reports International, Los Altos, v.40, n.6, p.1049-1057, dec. 1989.

KELLOGG, D. W.; TOMLINSON, D. J.; SOCHA, M. T.; JOHNSON, A. B. Effect of feeding zinc methionine complex an milk production and somatic cell count of daily cattle: Twelve-trial summary. Professional Animal Scientist, Charlottesville, v.20, p.295, 2004.

LANGWINSKI, D.; PATIÑO, H. O. A nutrição de ruminantes e os complexos orgânicos de minerais. São Paulo: Tortuga, 2001.

LUCCI, C. S. Nutrição e manejo de bovinos leiteiros. São Paulo: Manole, 1997.

MACHADO, P. F. Uso da levedura desidratada na alimentação de ruminantes. In: SIMPÓSIO SOBRE TECNOLOGIA DA PRODUÇÃO E UTILIZAÇÃO DA LEVEDURA DESIDRATADA NA ALIMENTAÇÃO ANIMAL, n., 1997, Campinas. Anais... Campinas: CBNA, 1997.p.111-128.

MAHAN, L. K.; STUMP, S. E. Krause: alimentos, nutrição \& dietoterapia. 9.ed. São Paulo: Roca, 1998. p.143-147.

MAYNARD, L. A.; LOOSLI, J. K.; HINTZ, H. F.; WARNER, R. G. Nutrição animal.3.ed. Rio de Janeiro: Freitas Bastos, 1984.

McDOWELL, L. R. Feedind minerals to cattle on pasture animal. Animal Feed Science Technology, Gainesvile, v.60, p.247-271, 1996.

MILLER, G. D.; JARVIS, J. K.; McBEAN, L. D. Handbook of dairy foods and nutricion. 2.ed. Boca Raton: CRC Press, 2000 .

MILLER, J. K.; RAMSEY, N.; MADSEN, F. C. The trace elements. In: CHURCH, D. C. (Ed.) The ruminant animal digestive physiology and nutrition. Englewood: Pretice Hall, 1988. p.342-400.

MORAES, S. S. Avaliação das concentrações de zinco, manganês e ferro no fígado de bovinos e ovinos de várias regiões do Brasil. Pesquisa Veterinaria Brasileira, Rio de Janeiro, v.18, n.3/4, p.107-110, 1998.

MORRISON, D. F. Multivariate statistical methods. São Paulo: McGraw Hill, 1990.

NATIONAL RESEARCH COUNCIL. Nutrient requirements of dairy cattle. 7.ed. Washington: National Academy Press, 2001. 
NICKERSON, S. C. Defense mechanisms of the cow. In: NATIONAL MASTITIS COUNCIL ANNUAL MEETING, n., 1990, New York. Proceedings... New York: editora, 1990. p.157.

NOCEK, J. E.; PATTON, R. S. Effect of chelated trace mineral supplementation for inorganic sources on production and health of Holstein cows. Journal of Dairy Science, Champaign, v.85, p.107- p.fin, 2002.

PEIXOTO, A. M.; MOURA, J. C.; FARB, V. P. Nutrição de bovinos: conceitos básicos e aplicados. 5.ed. Piracicaba: FEALQ, 1995.

PEREIRA, J. R. A.; NIZER, M. A.; DEKKERS, S. M.; RODRIGUES, F. J. Efeito da suplementação com quelato de zinco sobre a qualidade do leite de vacas da raça holandesa. In: ZOOTEC 2005, n., 2005, Campo Grande. Anais... Campo Grande: UEMS, 2005. Disponível em: <http://www.uems.br/zootec2005/>. Acesso em: 25 jun. 2007.

PHILPOT, W. N. Economics of mastitis control. Veterinary Clinics of North America-Large Animal Practice, Philadelphia, v.6, n.2, p.233-245, 1984.

POPOVIC, Z. Performance and udder health status of dairy cows influenced by organically bound zinc and chromium. 2004. Ph.D. Thesis, Faculty of Veterinary Medicine, University of Belgrade, Belgrade.

PROBST, C. S. W. Cicatrização das feridas e regeneração de tecidos específicos. In: SLATTER, D. Manual de cirurgia de pequenos animais. 2.ed. São Paulo: Manole, 1999. v.1.

RATNAKUMAR, A. V.; HAMZA, P. A.; CHOUDHURI, P. C. Treatment of subclinical mastitis in early lactation. Indian Veterinary Journal, Madras, v.73, n.9, p.970-972, sep. 1996.

REBHUN, W. C. Doenças do gado leiteiro. São Paulo: Roca, 2000.

RIBEIRO, M. E. R.; PETRINI, L. A.; AITA, M. F.; BALBINOTTI, M.; STUMPF JUNIOR, W.; GOMES, J. F.; SCHRAMM, R. C.; MARTINS, P. R.; BARBOSA, R. S. Relação entre mastite clínica, subclínica infecciosa e não infecciosa em unidades de produção leiteiras na região sul do Rio Grande do Sul. Revista Brasileira de Agrociência, Pelotas, v.9, n.3, p.287-290, jul./set. 2003.
SILVA, L. A. F.; SILVA, C. A.; BORGES, J. R. J.; FIORAVANTI, M. C. S.; BORGES, G. T.; ATAYDE, I. B. A clinical trial to assess the use of sodium hypochlorite and oxytetracycline on the healing of digital dermatitis lesions in the cattle. Canadian Veterinary Journal, Ottawa, v.46, n.4, p.345-348, 2005.

SMART, M. E.; GUDMUNDSON, J.; CHRISTENSEN, D. A. Trace mineral deficiencies in cattle: a review. Canadian Veterinary Journal-Revue Veterinaire Canadienne, Ottawa, v.22, n.12, p.372-376, 1981.

SMART, M.; CILBALUK, N. F. Role of nutritional supplements in bovine lameness review of nutritional toxicities. In: GREENOUGH, P. R.; WEAVER, A. D. Lamenes in cattle. 3.ed. Philadelphia: W. B. Saunder, 1997. p.145161.

SMITH, M. B.; AMOS, H. E.; FROETSCHEL, M. A. Hoof health and dietary interrelationships in lactating dairy cows. Diet Hoof Health, cidade, v., n., p.121-129, 1997.

SPEARS, J. W. Organic trace minerals in ruminant nutrition. Animal Feed Science and Technology, Amsterdam, v.58, n.1/2, p.151-163, apr. 1996.

UNITED STATES OF AMERICA. United States Departament Agriculture (USDA). Produção de leite brasileira. 2002. Disponível em: <http:// www.usda.gov.us>. Acesso em: 21 maio 2006.

VILELA, D. Leite? Bom para a saúde e melhor ainda para economia brasileira. 2002. Disponível em: <http:// www.cnpgl.embrapa.br>. Acesso em: 21 maio 2006.

VOLESKY, B. Biosorption of heavy metals. Boca Raton: CRC Press, 1990.

WAITZBERG, D. L. Nutrição enteral e paraenteral na prática clínica. 3.ed. Rio de Janeiro: Atheneu, 2004.

WHITAKER, D. A.; EAYRES, H. F.; AITCHISON, K. K.; KELLY, J. M. No effect of dietary zinc proteinate on clinical mastitis, infection rate, recovery rate and somatic cell count in dairy cow. The Veterinary Journal, London, v.153, n.2, p.197-204, mar. 1997.

ZAR, J. H. Biostatistical analysis. New Jersey: Prentice Hall, 1996. 
